
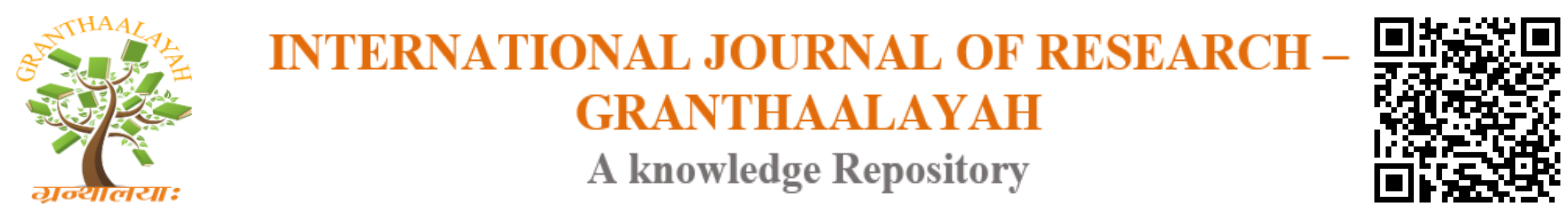

Science

\title{
APPLICATIONS OF CONSTRUCTION AN EOG TELEVISION CONTROL MODEL
}

\author{
Wang Ching-Sung ${ }^{* 1}$, Vincent Hoong Yong Sheng ${ }^{2}$, Wang Cheng-Jai ${ }^{1}$ \\ ${ }^{1}$ Department of Electronic Engineering, Oriental Institute of Technology, Taiwan \\ ${ }^{2}$ Department of Biomedical and Mechatroncis Engineering, Universiti Tunku Abdul Rahman, \\ Malaysia
}

\begin{abstract}
Speaking and writing are two common easiest mediums of communication for human. However, they are not applicable when it comes to handicapped who has hearing or speaking inability. Handicapped often encounter a hard time in expressing their feelings and thoughts to others. Furthermore, there are abundant of product in the market, which uses eye movement, light reflection theory and electrooculogram (EOG) as the input of their control system. These implication aims to ease the disabled to use modern devices. Therefore, a research is done on constructing an EOG Television Control Model to help the disabled to have remote on the television. By using the eye's electrical signal obtained via vertical and horizontal motion, user can easily control television by rolling or blinking their eyes.

Motivation/Background: The main motivation for this research is to look for an alternative solution to help patients especially those with physical disabilities to control television using eyes motions without difficulties. Moreover, selection for the best television monitoring method among all possible solution is also one of the research progress.

Method: The most important method being used in this research is by using EOG to detect eyes motion and convert each and every unique motion into a specific command for television monitoring action. Wireless communication device is an additional to allow long range television control using EOG signal.

Results: It is shown that the EOG signal for left and right and up and down motion of eyeballs differ with each other. Using the motion and by setting a threshold value to quantized the signal, a better quality television monitoring command is generated.

Conclusions: EOG signal allow user especially those with physical disabilities to monitor television with ease by performing unique eye rolling motion.

Keywords: Electrooculogram (EOG); Remote; Eye's Electrical Signal; Control Television.

Cite This Article: Wang Ching-Sung, Vincent Hoong Yong Sheng, and Wang Cheng-Jai. (2017). "APPLICATIONS OF CONSTRUCTION AN EOG TELEVISION CONTROL MODEL." International Journal of Research - Granthaalayah, 5(12), 357-362. https:// doi.org/10.29121/granthaalayah.v5.i12.2017.513.
\end{abstract}




\section{Introduction}

In this electronics era, in order to provide the best flexibility, performance and comfort ability to users, various creative and innovative inventions has been created through integration of basic products [1]. Some products used the theory of light reflection [2][3] while others implement EOG as part of their system structure [4][5][6]. Therefore, this research aims to integrate biomedical technology which in this proposal - the EOG Television Control System with spectacles or any possible eye accessories. EOG uses four contact pads that will be located on the top, bottom, left and right of the eye. Every eye movement and blinking status will generates a unique electrical signal. Utilizing the electrical signal generated, an EOG remote television can be done. Users with non-eye related inabilities could control television without depending on other person.

This research aims to allow patient with Amyotrophic Lateral Sclerosis (ALS), Motor Neuron Disease (MND), stoke or other physical inability problems to have simple and direct control on television. The current implementation, which is applied on ALS patient, is by using infrared or Charged Couple Device (CCD) recorder to detect user control. However, this proposed method is unstable and expensive. As compared to the method proposed in this research, it uses simple and direct circuit control, which leads to cheap and better stability performance. This can improve patient independencies and provide better entertainment for them. Patients can control television through wireless connection.

\section{Materials and Methods}

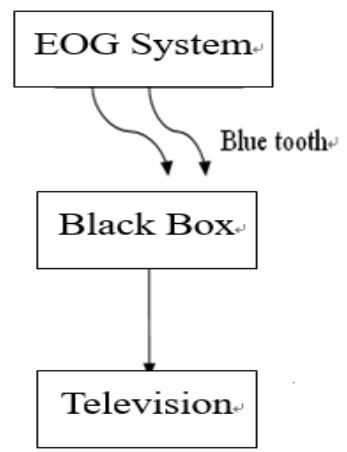

Figure 1: System Structure

The system structure is shown in Figure 1; electro ocular signal will be measured using EOG system. Depending on software configuration of the eye motion command, television is remotely controlled. EOG system and television is communicated using Bluetooth protocol.

The methods to measure electro ocular signal are categorized into two categories. The former category is the "in contact" method where it uses Electrooculography (EOG) to measure eye signal [7].

The latter method is "non-contact" method which uses either Infrared-oculography [2] or Infrared Video System (IRVS) [7]. The method proposed in this research uses "in contact" method which is EOG. The comparison between EOG and IRVS are shown in Table 1. 
Table 1: Comparison between EOG and IRVS

\begin{tabular}{|l|l|l|}
\hline & EOG & IRVS \\
\hline \multirow{3}{*}{ Advantage } & $\begin{array}{l}\text { 1、High Sensitivity } \\
\text { 2、 Easy } \\
\text { 3、Cheap }\end{array}$ & $\begin{array}{l}\text { 1、Wireless connection } \\
\text { 2、Simple device }\end{array}$ \\
\hline Disadvantage & $\begin{array}{l}\text { 1、Baseline drift } \\
\text { 2、Not suitable for long } \\
\text { duration }\end{array}$ & $\begin{array}{l}\text { 1、 Device need to be properly } \\
\text { equipped } \\
\text { 2、Sensitive to light }\end{array}$ \\
\hline
\end{tabular}

Due to the expensive cost and requirement for CCD of IRVS, EOG is selected in this research. The flow chart of the main program of the black box to control the television is shown in Figure 2. Data will be received by the black box via Bluetooth. A specific threshold is set in order to discretize EOG signal for easy identification of blinking or rolling of eyes.

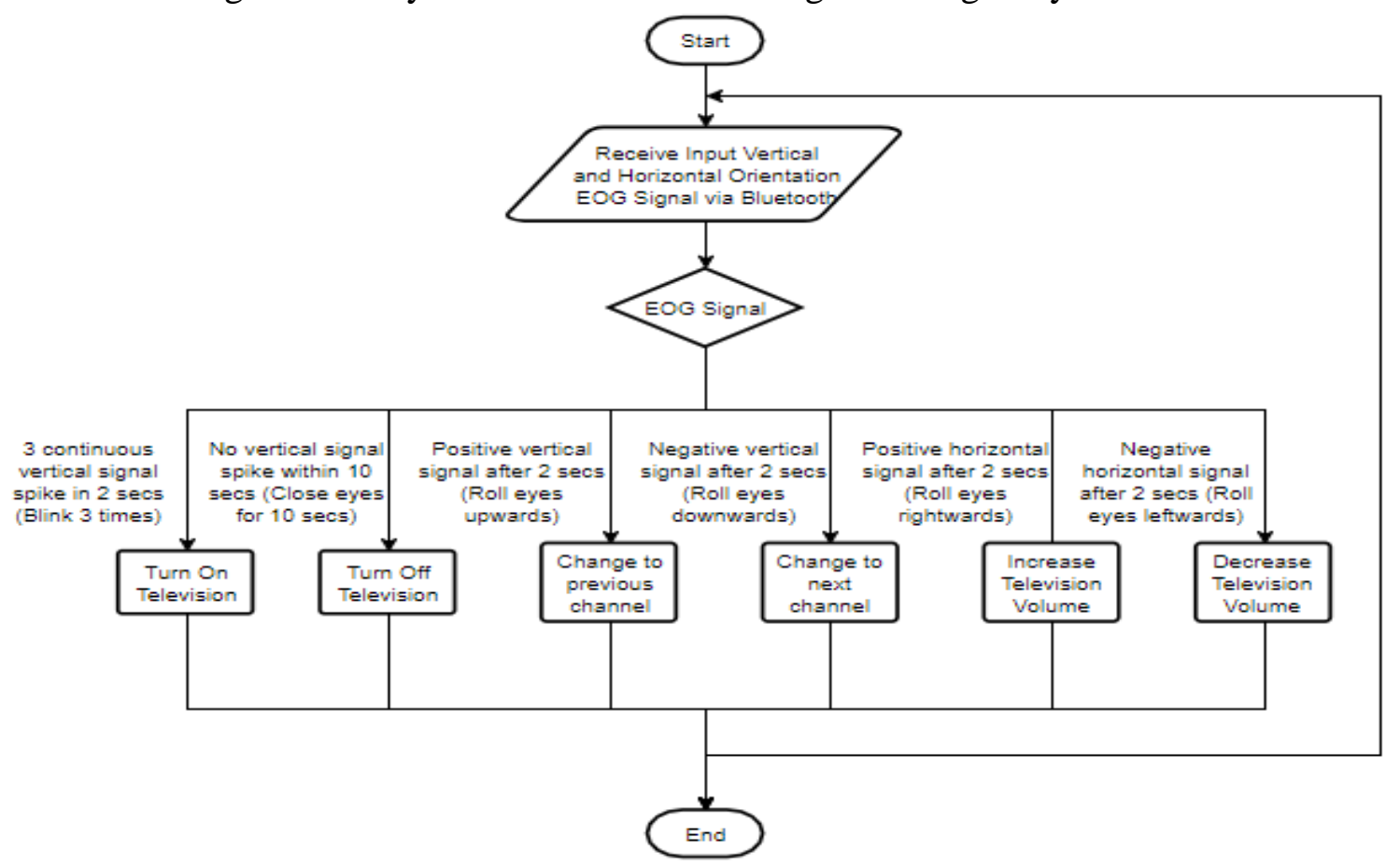

Figure 2: Flowchart of the Main Program

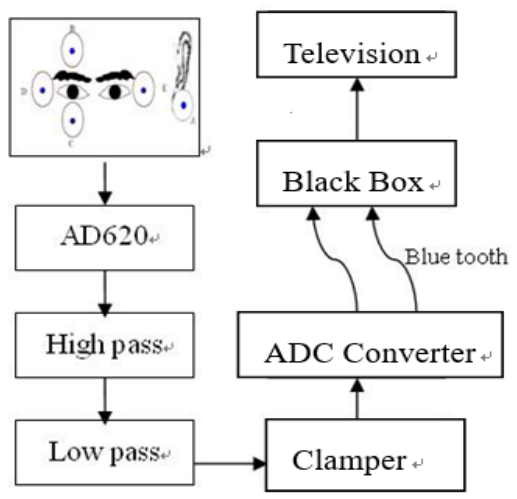

Figure 3: Hardware Structure 


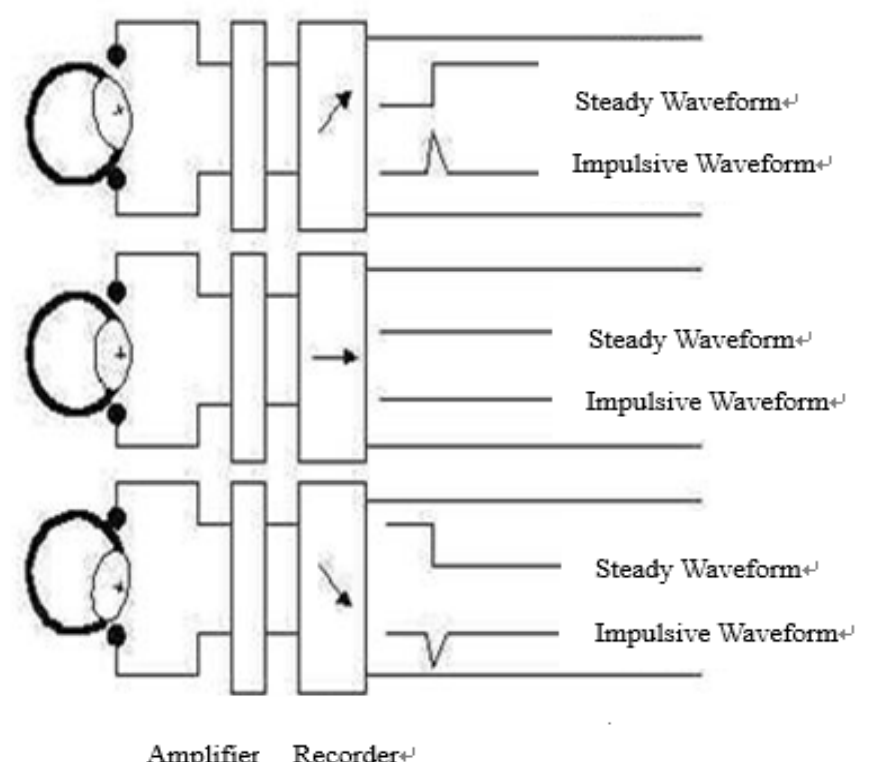

Figure 4: EOG Signal Responses

The EOG signal measure is sent to a hardware device as shown in Figure 3. The electro ocular signal for rolling upwards and downwards eye motion is as shown in Figure 4. Eye motion can be detected based on the EOG signal generated. This method can detect up to a precision of 3 degrees of horizontal deflection and 5 degrees of vertical deflection.

Table 2 show the characteristic of different biomedical signal. Due to the small maximum amplitude that can be generated by EOG which is $3.5 \mathrm{mV}$, the signal is amplify by 2000 times. High pass filter is used to filter frequency that is lower than $0.033 \mathrm{~Hz}$. An $8^{\text {th }}$ order Butterworth low pass filter is then used to filter off frequency that is higher than 34Hz. An Analogue-toDigital Converter (ADC) can only convert positive voltage. Therefore, a clamping circuit is used to shift the voltage by positive $3 \mathrm{~V}$ to allow ADC conversion. The digital signal is then sent to a control system mounted on television via Bluetooth to perform operation.

Table 2: Characteristics of Biomedical Signal

\begin{tabular}{|l|l|l|}
\hline Signal & Amplitude(mV) & Frequency range(Hz) \\
\hline ECG & $0.02-5.0$ & $0.05-100$ \\
\hline EEG(surface electrode) & $0.0002-0.3$ & $\mathrm{DC}-150$ \\
\hline EEG(nailelectrode) & $0.01-50.0$ & $\mathrm{DC}-150$ \\
\hline EMG & $0.1-5.0$ & $\mathrm{DC}-10000$ \\
\hline EGG & $0.01-1.0$ & $0.05-0.5$ \\
\hline ERG & $0-0.9$ & $\mathrm{DC}-15$ \\
\hline EOG & $0.05-3.5$ & $0.034-34$ \\
\hline
\end{tabular}

The amplitude of signals decreases as the wakefulness level decreases [8]. Therefore, a threshold logic control is needed to trigger each command action. 


\section{Results and Discussions}

This study shows the hardware circuit for EOG measurement and signal filtering. Four contact pads is placed on the B, C, D and E location around the eyes as shown in Figure 5. Other than that, one contact pad is placed on the ear (position A) as reference voltage.

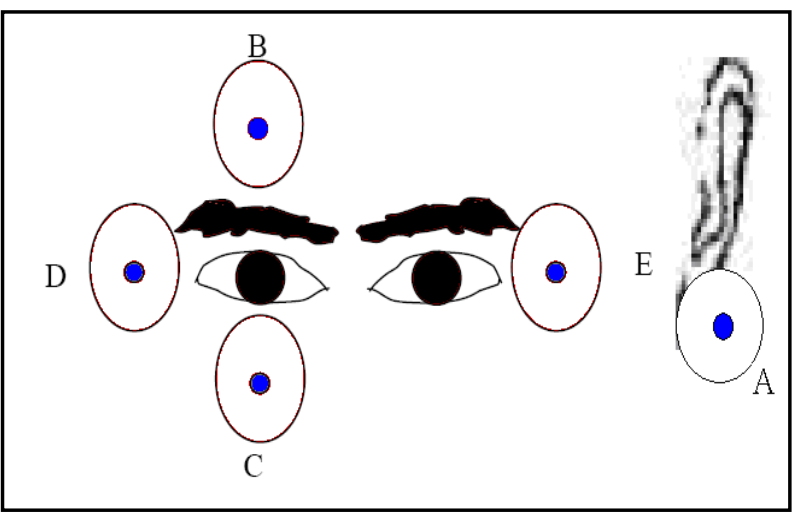

Figure 5: Location of Contact Pad

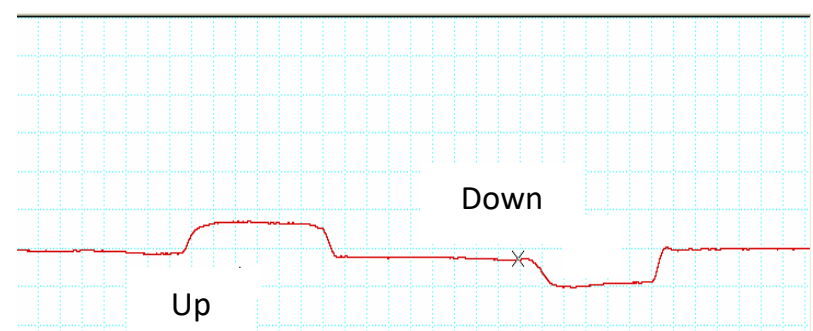

Figure 6: EOG Signal of Vertical Motion

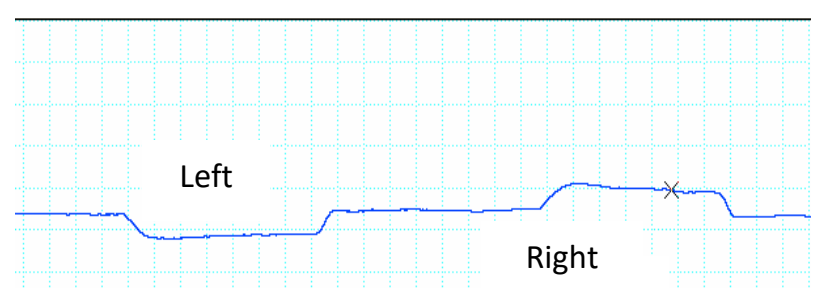

Figure 7: EOG Signal of Horizontal Motion

According to the result obtained, any eye motion that include rolling and blinking will produced electrical signal as shown in Figure 6 and Figure 7. The amplitude of the EOG signal varies depending on the angle of deflection of the eyes from its stationary position. The larger the deflected angle, the larger the signal amplitude.

Finally, it is also identified that the amplitude of the signal generated changes according to the level of wakefulness. The higher the wakefulness level the higher the amplitude of signal 
generated. Other than that, the blinking frequency can also increase when wakefulness level decreases. By utilizing this information, an optimize threshold level is set to gives better control for the users.

\section{Conclusions and Recommendations}

The EOG Television Control Model is simple and cheap as compare to IRVS. It allows user to remotely control television using eye motion. The amplitude of the EOG signal increase according to the angle of deflection. The larger the deflected angles of the eyes upwards from the stationary position, the larger the amplitude of vertical EOG signal. The larger the deflected angles of the eyes rightwards from the stationary position, the larger the amplitude of horizontal EOG signal.

\section{References}

[1] M. Betke, J. Gips, and P. Fleming, "The camera mouse: visual tracking of body feature to provide computer access for people with severe disabilities," IEEE Transaction on Neural Systems and Rehabilitation Engineering, vol. 10, no. 1, pp. 1-10, 2002

[2] C. H. Morimoto, D. Koons, A. Amit, M.Flickner, and S. Zhai, 73 "Keeping an eye for HCI," Processing of XII Brazilian Symp.Computer Graphics and Image, pp. 171-176, 1999.

[3] LC Technologies, INC. Available: http://www.eyegaze.com/INDEX.htm. June 28 2006[data accessed]

[4] D. Kumar and E. Poole, "Classification of EOG for human computer interface," Conference in the Second Joint EMBS/BMES, vol. 1, pp. 23-26, Oct. 2002.

[5] K. S. Park and K. T. Lee, "Eye-controlled human computer interface using the line-of-sight and the intentional blink, "Computer Engineering, vol. 30, no.3, pp. 463-473, 1996.

[6] L. Young and D. Sheena, "Survey of eye movement recording methods," Behav. Res. Meth. Instrum, vol. 7, no. 5, pp.397-429, 1975.

[7] A. T. Duchowski, Eye Tracking Methodology: Theory and Practice London Springer- Verlag, pp 55-65, 2002.

[8] Drowsiness Detection by ElectrooculogramSignal Analysis in Driving Simulator Conditions for Gold Standard Signal Generation (2013). Proceedings of the International Conference on Biomedical Electronics and Devices. doi:10.5220/0004241500570063

*Corresponding author.

E-mail address: ff020@ mail.oit.edu.tw 